\section{Serologic Assessment of Possibility for MERS-CoV Infection in Equids}

\section{Benjamin Meyer, Ignacio García-Bocanegra, Ulrich Wernery, Renate Wernery, Andrea Sieberg, Marcel A. Müller, Jan Felix Drexler, Christian Drosten, and Isabella Eckerle}

Author affiliations: University of Bonn Medical Centre, Bonn, Germany (B. Meyer, A. Sieberg, M.A. Müller, C. Drosten, J.F. Drexler, I. Eckerle); Universidad de Córdoba, Córdoba, Spain (I. García-Bocanegra); and Central Veterinary Research Laboratory, Dubai, United Arab Emirates (U. Wernery, R. Wernery) DOI: http://dx.doi.org/10.3201/eid2101.141342

To the Editor: In 2012, a novel coronavirus termed Middle East respiratory syndrome coronavirus (MERS$\mathrm{CoV}$ ) emerged on the Arabian Peninsula; the virus has been responsible for $>800$ human cases. Recently, evidence of MERS-CoV infection in dromedaries was obtained from the Canary Islands, the Arabian Peninsula, and Africa (1$3)$. Viral sequences from dromedaries and from humans infected with MERS-CoV were highly similar, suggesting a prominent role of dromedaries as an animal reservoir of the virus (4). However, the serologic assessment of other animal species has been incomplete. Investigations of domestic animal species have been restricted to goats, sheep, and cattle (3) and a limited study of horses $(\mathrm{n}=3)(5)$. No evidence of recent infection was found in either study.

Whereas most known CoVs have a highly restricted host range in vitro and in vivo, MERS-CoV has been found to infect a broad range of cell cultures derived from Old and New World camelids as well as humans, primates, bats, pigs, and goats (6). MERS-CoV uses the receptor dipeptidyl-peptidase-4 (DPP-4) to enter its host cell (7). Sequence comparison between the receptor-binding domain of the MERS-CoV spike protein and several mammalian DPP-4 sequences showed a higher percentage identity in the amino acid residues critical for virus entry between human and horse DPP-4 than between human and dromedary DPP-4 (8). It has been shown that MERS-CoV can use horse DPP-4 expressed on nonsusceptible cells (9), but no data are available on susceptibility of primary horse cells. Therefore, members of the family Equidae, which include domestic horses, donkeys, and mules, might be susceptible to MERS-CoV infection. According to the Food and Agricultural Organization of the United Nations (http://faostat. fao.org), $>800,000$ equids (horses, mules, and donkeys) are present on the Arabian Peninsula, but their role as putative MERS-CoV animal reservoirs has not been investigated. Therefore, we assessed in vitro susceptibility of primary horse cells to MERS-CoV infection and searched for serologic evidence of infection with MERS-CoV in equids originating from Spain and the United Arab Emirates.

Primary cells derived from the kidney of 2 horses (termed PN-R and PFN-R) and an interferon-deficient primate cell line (VeroB4) were infected with MERS-CoV at a multiplicity of infection of 0.5 PFUs. Virus replication was quantified by real-time reverse transcription PCR (MERS-CoV upE assay) (10) and by plaque assay in Vero cells to confirm the production of infectious virus particles. Both cell lines showed clear cytopathic effects, an increase of viral RNA, and production of infectious virus progeny (Figure, panels A, B).

To investigate equids for signs of infection with MERS$\mathrm{CoV}$, we collected 1,053 serum samples from MERS-CoVendemic and -nonendemic areas: 192 samples from adult
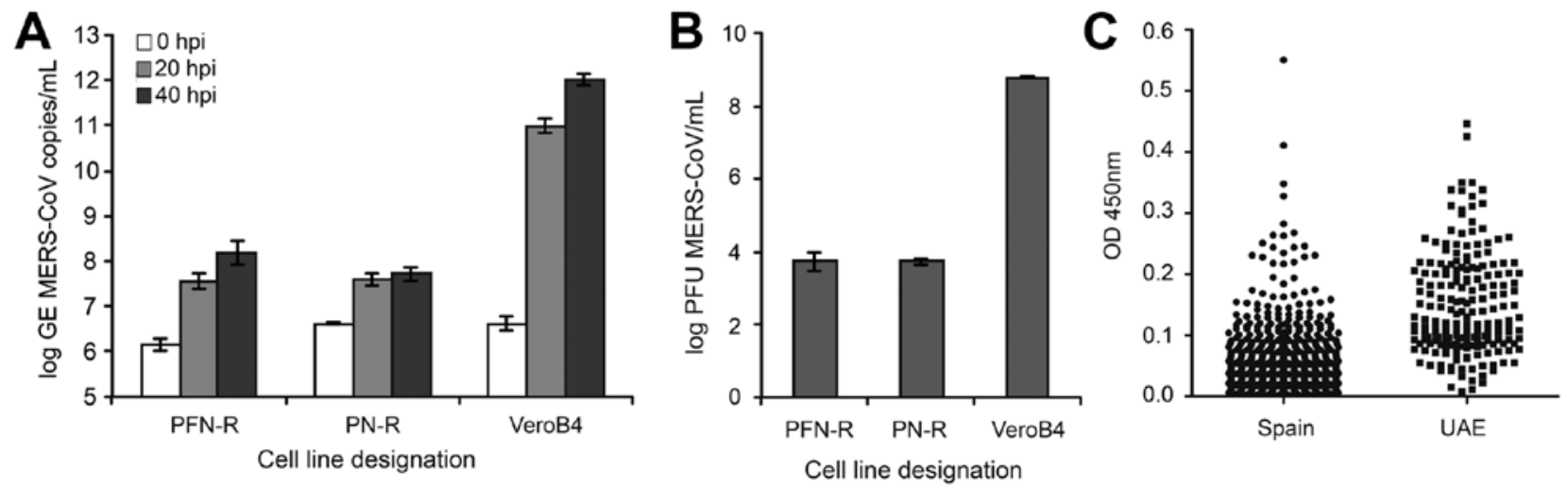

Figure. Analysis of the replication of Middle East respiratory syndrome coronavirus (MERS-CoV) in primary horse kidney cell lines and origin of equine serum samples. A, B) Cells were seeded at densities of $2 \times 10^{5} \mathrm{cells} / \mathrm{mL}$ and infected in triplicate with a multiplicity of infection of 0.5 infectious MERS-CoV units/cell. After incubation for $1 \mathrm{~h}$, cells were washed twice and supernatants were harvested at 0,20 , and $40 \mathrm{~h}$ postinfection (hpi). The replication level is given as the log of the genome equivalents (A) or as PFUs (B). Error bars indicate SDs; PF-N and PFN-R indicate the 2 primary horse cell lines; VeroB4 is an interferon-deficient primate cell line. C) Distribution of optical density (OD) values (450 nm) of equine serum samples originating from Spain or the United Arab Emirates (UAE). 
endurance horses from the United Arab Emirates that were collected for routine veterinary purposes; and 861 samples from 697 horses, 82 donkeys, and 82 mules in Spain. Because the reactivity of equid serum against MERS-CoV has not been investigated, we established a 2-stage algorithm for serologic testing that did not involve the determination of reactivity cutoff values. The screening stage involved testing of all serum samples by using a previously described ELISA with the spike protein S1-domain of MERS-CoV as the test antigen (4). The ELISA was adapted for use with horse serum by exchange of the secondary antibody. All serum samples reacted with low to medium OD values (range $0.0-0.55$ ) (Figure, panel C). We then tested the 50 most reactive serum samples (optical density range $0.22-0.55$ ) by using recombinant immunofluorescent and microneutralization assays (1). These assays are more specific than the ELISA assay and therefore can be used for confirmation. None of the tested serum samples showed reactivity in the recombinant immunofluorescent or microneutralization assays; this finding suggests that no previous exposure of equids to MERS-CoV has occurred in the United Arab Emirates and Spain.

Identifying all potential animal reservoirs is a critical step in controlling zoonotic diseases. Molecular data suggest that horses may be highly susceptible to MERS-CoV because of their high similarity in DPP-4 amino acids at positions critical for binding of the MERS-CoV spike protein (8). Our in vitro data confirm the susceptibility of primary horse cells, showing production not only of viral RNA but also of infectious virus progeny, which is a prerequisite for transmission. The lower replication observed in horse cells than in VeroB4 cells may be the result of a difference in the interferon competence of the cells; replication levels in horse cells are comparable to those in bat cells (6). Although we did not find evidence for equid infections with MERS-CoV in this study, the general susceptibility on the cell culture level suggests that equids from MERS-CoV-endemic areas, such as Africa and the Arabian Peninsula, should be further investigated for possible infection with MERS-CoV.

\section{Acknowledgments}

We thank Dagmar Hensel for excellent technical help and Matthias Lenk for horse cell lines. We also thank Victor Corman, Monika Eschbach-Bludau, Tobias Bleicker, and Sebastian Brünink for help with horse serum samples.

This study was supported by the European Commission under project ANTIGONE (contract no. 278976) and the German Centre for Infection Research.

\section{References}

1. Meyer B, Muller MA, Corman VM, Reusken CB, Ritz D, Godeke GJ, et al. Antibodies against MERS coronavirus in dromedary camels, United Arab Emirates, 2003 and 2013. Emerg Infect Dis. 2014;20:552-9. http://dx.doi.org/10.3201/eid2004.131746
2. Reusken CB, Haagmans BL, Muller MA, Gutierrez C, Godeke GJ, Meyer B, et al. Middle East respiratory syndrome coronavirus neutralising serum antibodies in dromedary camels: a comparative serological study. Lancet Infect Dis. 2013;13:859-66. http://dx.doi.org/10.1016/S1473-3099(13)70164-6

3. Hemida MG, Perera RA, Wang P, Alhammadi MA, Siu LY, Li M, et al. Middle East Respiratory Syndrome (MERS) coronavirus seroprevalence in domestic livestock in Saudi Arabia, 2010 to 2013. Euro Surveill. 2013;18:20659.

4. Memish ZA, Cotten M, Meyer B, Watson SJ, Alsahafi AJ, Al Rabeeah AA, et al. Human infection with MERS coronavirus after exposure to infected camels, Saudi Arabia, 2013. Emerg Infect Dis. 2014;20:1012-5. http://dx.doi.org/10.3201/eid2006.140402

5. Alexandersen S, Kobinger GP, Soule G, Wernery U. Middle East respiratory syndrome coronavirus antibody reactors among camels in Dubai, United Arab Emirates, in 2005. Transbound Emerg Dis. 2014;61:105-8. http://dx.doi.org/10.1111/tbed.12212

6. Eckerle I, Corman VM, Muller MA, Lenk M, Ulrich RG, Drosten C. Replicative Capacity of MERS coronavirus in livestock cell lines. Emerg Infect Dis. 2014;20:276-9. http://dx.doi. org/10.3201/eid2002.131182

7. Raj VS, Mou H, Smits SL, Dekkers DH, Muller MA, Dijkman R, et al. Dipeptidyl peptidase 4 is a functional receptor for the emerging human coronavirus-EMC. Nature. 2013;495:251-4. http://dx.doi.org/10.1038/nature12005

8. Bosch BJ, Raj VS, Haagmans BL. Spiking the MERS-coronavirus receptor. Cell Res. 2013;23:1069-70. http://dx.doi.org/10.1038/ cr.2013.108

9. Barlan A, Zhao J, Sarkar MK, Li K, McCray PB Jr, Perlman S, et al. Receptor variation and susceptibility to Middle East respiratory syndrome coronavirus infection. J Virol. 2014;88: 4953-61. http://dx.doi.org/10.1128/JVI.00161-14

10. Corman VM, Eckerle I, Bleicker T, Zaki A, Landt O, EschbachBludau M, et al. Detection of a novel human coronavirus by real-time reverse-transcription polymerase chain reaction. Euro Surveill. 2012;17:20285.

Address for correspondence: Christian Drosten, Institute of Virology, University of Bonn, Sigmund Freud Str. 25, 53105 Bonn, Germany; email: drosten@virology-bonn.de

\section{Autochthonous Dengue Fever Imported to England from Japan, 2014}

\section{Gotaro Kojima}

Author affiliation: Japan Green Medical Centre, London, UK

DOI: http://dx.doi.org/10.3201/eid2101.141581

To the Editor: Dengue fever, a mosquito-borne disease caused by dengue virus, can be asymptomatic or result in a variety of clinical manifestations, including fever, headache, myalgia, arthralgia, and rash (1). Severe cases can cause shock or severe hemorrhage (1). During the past 50 years, dengue has become a public health concern worldwide, rapidly spreading geographically, mainly in tropical and subtropical countries (1). 